\title{
PON1 status evaluation in patients with chronic arterial occlusion of lower limbs due to atherosclerosis obliterans
}

\author{
Magdalena P. Kasprzak ${ }^{1}$, Maria Iskra ${ }^{1}$, Wacław Majewski², Magdalena Budzyń-Napierała ${ }^{1}$, \\ Bogna Gryszczyńska ${ }^{1}$, Krzysztof Strzyżewski ${ }^{1}$, Jakub Kasprzak ${ }^{3}$
}

\author{
1Department of General Chemistry, Chair of Chemistry and Clinical Biochemistry, \\ Poznan University of Medical Sciences, Poznan, Poland \\ ${ }^{2}$ Department of General and Vascular Surgery, Poznan University of Medical Sciences, \\ Poznan, Poland \\ ${ }^{3}$ Department of Obstetrics and Gynecology with Pregnancy Pathology, \\ Raszeja Hospital, Poznan, Poland \\ Submitted: 26 July 2012 \\ Accepted: 12 December 2012
}

Arch Med Sci 2014; 10, 6: 1101-1108

DOI: 10.5114/aoms.2014.41348

Copyright $\odot 2014$ Termedia \& Banach

\author{
Corresponding author: \\ Magdalena P. Kasprzak \\ Department \\ of General Chemistry \\ Chair of Chemistry \\ and Clinical Biochemistry \\ Poznan University \\ of Medical Sciences \\ 6 Grunwaldzka St \\ 60-780 Poznan, Poland \\ Phone: +48 6185465 90/98 \\ Fax: +48 618546599 \\ E-mail: magdarut@ump.edu.pl
}

\begin{abstract}
Introduction: Human paraoxonase (PON1) is a calcium-dependent enzyme physically associated with $\mathrm{HDL}$, and it is believed to contribute to the atheroprotective effect of HDL. The aim of the study was to evaluate PON1 status in patients with atherosclerosis obliterans as an effect of ischemia regarding its activity and phenotype distribution.

Material and methods: The study group consisted of patients with chronic arterial occlusion of the lower limbs due to atherosclerosis obliterans (AO). The patients were divided into two groups according to the degree of ischemia: moderate $(\mathrm{MI})$, and critical $(\mathrm{Cl})$. The ratio of the hydrolysis of salt-stimulated PON 1 activity to the hydrolysis of phenylacetate was used to assign individuals to one of three possible phenotypes (low activity - A, medium activity - AB, high activity - B). It was observed that PON1 arylesterase activity was affected by ischemia of the lower limbs depending on its degree. Results: The odds ratio and the relative risk analysis showed that the patients with moderate ischemia are much more often characterized by phenotype A than by phenotype B. The low activity phenotype A occurs over twice as often in patients with chronic ischemia of the lower limbs as in individuals from the control group $(\mathrm{OR}=2.125 ; 1.96$ to $3.776, p=0.0143)$. Conclusions: This study presents the low activity phenotype $A$ in relation to the risk of ischemia of the lower limbs due to atherosclerosis and shows the potentially important role of PON1 in conclusion of the process leading to intensification of ischemia degree.
\end{abstract}

Key words: low activity phenotype, risk of ischemia, arylesterase, paraoxonase activity.

\section{Introduction}

Human paraoxonase (PON1) is a calcium-dependent ester hydrolase and the PON gene is a member of a multigene family which includes at least two other genes, PON2 and PON3 [1]. The PON1 is an enzyme synthesized in the liver, physically associated with HDL, and it is believed to contribute to the atheroprotective effect of $\mathrm{HDL}[2,3]$. The PON1 inhibits oxidation of low-density lipoprotein (LDL) in vitro [4, 5]. Genetic deletion of PON1 is associated with increased susceptibility of LDL to oxidation 
ex vivo, increased measures of macrophage oxidative stress, and increased lesion size in animal models of atherosclerosis; conversely, overexpression of the human PON1 transgene in mice results in reduced aortic lesion size [6-9]. Serum PON1 activity has been found to be reduced in metabolic syndrome, diabetes mellitus, advancing age, atherosclerotic vascular disease, chronic ischemia of the lower limbs, chronic liver damage, cancer, smoking and more [10-18]. It has been postulated that PON1 should be treated as a component of the plasma antioxidant system [19].

Human PON1 has two main genetic polymorphisms both due to amino acid substitutions, one involving glutamine (A or Q genotype) and arginine (B or R genotype) at position 192 and the other leucine (L genotype) and methionine (M genotype) at position 55 [20, 21]. The serum activity of PON1 varies among individuals, and this difference is chiefly related to the position-192 polymorphism of the PON1 gene [22]. Therefore, the population can be subdivided into three phenotypic groups: $A$ represents low, $A B$ intermediate, and $B$ high enzyme activity of PON1. The ratio of salt-stimulated PON1 activity to arylesterase activity is used for the definition of phenotypes [20-22]. The PON1Q192R polymorphism has been studied more extensively and has been shown to affect the activity of PON1 alloenzymes with respect to both organophosphate detoxification and lipoprotein oxidation [23]. Several case-control studies have shown the positive association of PON1-Q192R polymorphism with coronary heart disease (CHD) [24-27]. In contrast, the other studies reported no such correlation $[28,29]$. The measurement of the enzymatic activity of PON1 polymorphic forms shows substrate specificity [30]. Arylesterase activity with phenyl acetate gives about equal weight to both $\mathrm{Q}$ and $\mathrm{R}$ isozymes, because both have about the same specific activity. Diazoxon hydrolysis favors somewhat the $\mathrm{Q}$ isozyme, and paraoxon hydrolysis considerably favors the $R$ isozyme; the degree of this bias depends on the $\mathrm{pH}$ selected for the assay, as well as the salt concentration [28]. Further analysis is needed to find the substrate that best represents the protective role of PON1. The results of past analysis of pharmacogenetic and hereditary metabolic conditions suggest making the use of patient phenotypes to identify the critical genotypes at first, and then determining the molecular basis of the association [28]. In this light, determination of PON1 activity in addition to genotype (referred to as PON1 status) has been postulated to be more important than PON1 genotype alone [31-33]. Most of the studies in this field are associated with coronary artery disease, but we decided to focus our attention on patients with peripheral artery disease, to evaluate the phenotype distribution of PON1 and its activities in a group of patients with atherosclerosis obliterans as an effect of ischemia of the lower limbs intensity.

\section{Material and methods}

\section{Experimental subjects}

The group of patients studied consisted of 47 males with chronic arterial occlusion of lower limbs due to atherosclerosis obliterans (AO), aged 49-79 years, who were admitted to the Department of General and Vascular Surgery at the University of Medical Sciences, Poznan, Poland. All patients underwent arteriography of the lower limbs and ultrasound measurement of ankle pressure, and were treated surgically (implantation of aorto-bi-femoral prostheses). The patients were divided into two groups according to the degree of ischemia: moderate (MI), $n=22$, and critical (Cl), $n=25$. The $\mathrm{MI}$ is characterized by intermittent claudication, ankle pressure $\geq 50 \mathrm{~mm} \mathrm{Hg}$, and $\mathrm{Cl}$ by rest pain, ankle pressure $<50 \mathrm{~mm} \mathrm{Hg}$ and ulcers or necrosis of the lower limbs. The control subjects were 20 blood donors, healthy males aged 22-49 years, who underwent a medical check-up before having blood taken in the fasting state. Overweight subjects and those with diabetes and hypertension were excluded from both the study and the control groups. Neither group received any special lipid-lowering diet, nor were treated with angiotensin receptor blockers or antioxidant drugs. Ninety percent of patients studied received acetylsalicylic acid, $70 \%$ were on statin therapy, and $30 \%$ of patients were treated with angiotensin-converting enzyme inhibitors. About $65 \%$ of patients were heavy smokers. Biochemical analysis of the subjects in the investigation are shown in Table I. Fully informed consent was obtained, and the study protocol was approved by the Ethics Committee of Poznan University of Medical Sciences.

\section{Reagents and apparatus}

All the reagents used in the study were of analytical grade, and purchased from Sigma Chemical Company. The spectrophotometric measurements were carried out on a Meretech UV/VIS SP 8001 Spectrophotometer.

\section{Assay for arylesterase activity}

The assay for the arylesterase activity of PON1 was performed according to the Gan method [34]. In brief, the assay was run in a cuvette in $20 \mathrm{mM}$ Tris/ $\mathrm{HCl}$ buffer containing $1.0 \mathrm{mM} \mathrm{CaCl}$, and $1.0 \mathrm{mM}$ phenylacetate. The reaction was initiated by the addition of the enzyme ( $5 \mu$ l of plasma), and the 
Table I. Biochemical characteristics of patients

\begin{tabular}{|lcccc|}
\hline Parameter & AO $(n=47)$ & $\mathrm{MI}(n=22)$ & $\mathrm{Cl}(n=25)$ & Value of $p$ \\
\hline Age & $63.2 \pm 8.8$ & $67.72 \pm 9.27$ & $66.94 \pm 7.94$ & NS \\
\hline Triacylglycerol (TAG) [mmol/l] & $1.99 \pm 0.9$ & $1.74 \pm 1.19$ & $2.03 \pm 0.74$ & NS \\
\hline Total cholesterol (TC) [mmol/l] & $5.58 \pm 1.23$ & $5.64 \pm 0.85$ & $5.39 \pm 1.39$ & NS \\
\hline LDL cholesterol [mmol/l] & $3.48 \pm 1.01$ & $3.50 \pm 0.88$ & $3.23 \pm 1.13$ & NS \\
\hline HDL cholesterol $[\mathrm{mmol} / \mathrm{l}]$ & $1.24 \pm 0.27$ & $1.34 \pm 0.34$ & $1.15 \pm 0.27$ & $0.0384, \mathrm{NQS}$ \\
\hline LDL/HDL & $2.68 \pm 1.08$ & $2.37 \pm 1.03$ & $3.30 \pm 0.95$ & 0.0328 \\
\hline TC/HDL & $4.58 \pm 1.2$ & $4.56 \pm 0.99$ & $4.63 \pm 1.4$ & $\mathrm{NS}$ \\
\hline Arylesterase/HDL & $40.94 \pm 22.28$ & $46.59 \pm 27.01$ & $37.86 \pm 16.87$ & $\mathrm{NS}$ \\
\hline Uric acid [mg/dl] & $5.1 \pm 1.3$ & $5.2 \pm 1.2$ & $5.6 \pm 1.7$ & $\mathrm{NS}$ \\
\hline CRP $[\mathrm{mg} / \mathrm{l}]$ & $24 ; 8.88-180$ & $10.95 ; 8.88-26.6$ & $30.7 ; 13-177$ & 0.0006 \\
\hline
\end{tabular}

NS - not significant, NQS - not quite significant.

increase in absorbance at $270 \mathrm{~nm}$ was recorded. Blanks without enzyme were used to correct the spontaneous hydrolysis of phenylacetate. Arylesterase activity was calculated from the molar extinction coefficient $\left(\varepsilon=1310 \mathrm{M}^{-1} \mathrm{~cm}^{-1}\right)$ of phenol produced. A unit of arylesterase activity is defined as $1 \mu \mathrm{mol}$ of phenylacetate hydrolyzed per minute under the above assay conditions.

\section{Assay for paraoxonase activity}

The paraoxonase activity in plasma was measured with paraoxon as a substrate in a cuvette with $50 \mathrm{nM}$ Tris/ $\mathrm{HCl}$ buffer containing $1.0 \mathrm{mM}$ $\mathrm{CaCl}_{2}$ at $\mathrm{pH} 10.5$ and $1.0 \mathrm{M}$ of paraoxon. The reaction was initiated by the addition of enzyme $(5 \mu \mathrm{l}$ plasma), and the increase in absorbance was recorded at $412 \mathrm{~nm}$. The activity of PON1 stimulated by $1.0 \mathrm{M} \mathrm{NaCl}$ was performed as above [34].

\section{Paraoxonase phenotyping}

The phenotypes distribution of PON1 was determined by the dual substrate method [28]. The ratio of the hydrolysis of salt-stimulated PON1 activity to the hydrolysis of phenylacetate was used to assign individuals to one of the three possible $(A, A B, B)$ phenotypes. Cutoff values between phenotypes were as follows: type $A A$, ratio < 3.0; type $A B$, ratio 3.0-7.0; type $B B$, ratio $>7.0$.

\section{Lipid parameters}

Total, HDL- and LDL-cholesterol (TC, chol-HDL, chol-LDL) and triacylglycerol (TAG) concentrations in plasma were estimated by using enzymatic kits from Boehringer Mannheim Biochemica. The concentration of uric acid in plasma was determined by the reaction with uricase using Sigma Chemical Company diagnostic kits.

\section{Statistical analysis}

Standard methods (Kolmogorov-Smirnov and Shapiro-Wilk) were used to assess distribution normality of variables. The values were expressed as means \pm SD, and differences between the means were assessed with Student's $t$-test. For some of them, medians (minimum-maximum) were used when the normality test failed. Nonparametric methods (Kruskal-Wallis) were used to compare data that did not pass the normality test. Statistical analysis for the effects of different variables on the serum PON1 activity and phenotypes was carried out by one-way ANOVA. Allele frequencies were determined by the gene counting method and departure from the Hardy-Weinberg equilibrium was evaluated by the $\chi^{2}$-test. All calculated $p$ values were two-sided and $p \leq 0.05$ was considered significant.

\section{Results}

\section{Arylesterase activity}

Comparison of the results obtained for the control group with those for the $\mathrm{AO}$ group indicates the impact of lower limb ischemia on the enzymatic PON1 activity due to atherosclerosis progress. The arylesterase activity of PON1, measured with phenyl acetate as a substrate, was found to be significantly lower in the $\mathrm{AO}$ group in comparison to the control group $(49.35 \pm 27.13 \mathrm{U} / \mathrm{ml}$ and $85.30 \pm 35.05 \mathrm{U} / \mathrm{ml}$, respectively, $p=0.0001$ ). The PON1 arylesterase activity in the $A O$ group was affected by ischemia of the lower limbs. In the $\mathrm{Cl}$ group, reduced activity was observed in comparison with the $\mathrm{MI}$ group $(45.76 \pm 21.97 \mathrm{U} / \mathrm{ml}$ and $55.17 \pm 32.20 \mathrm{U} / \mathrm{ml}$, respectively) and with the control group $(85.30 \pm 35.05 \mathrm{U} / \mathrm{ml} ; p=0.0003$ for $\mathrm{Cl}$ and $p=0.0151$ for MI) (Table II). Moreover, 
Table II. Distribution of PON1 activities in accordance with ischemia intensity

\begin{tabular}{|lccc|}
\hline & $\begin{array}{c}\text { PON1 arylesterase } \\
{[\mathrm{U} / \mathrm{ml}]}\end{array}$ & $\begin{array}{c}\text { PON1 paraoxonase activity } \\
{[\mathrm{U} / \mathrm{l}]}\end{array}$ & $\begin{array}{c}\text { PON1 stimulated activity } \\
{[\mathrm{U} / \mathrm{l}]}\end{array}$ \\
\hline $\mathrm{MI}$ & $55.17 \pm 32.20^{*}$ & $73.50 ; 20-391^{* *}$ & $130 ; 50-814$ \\
\hline $\mathrm{Cl}$ & $45.76 \pm 21.97^{* * *}$ & $108.50 ; 7.4-527^{*}$ & $196 ; 7-1408^{\dagger}$ \\
\hline Control group & $85.30 \pm 35.05$ & $190.12 \pm 76.73$ & $197.5 ; 118-736$ \\
\hline Value of $p$ & $<0.0001$ & 0.0016 & 0.0294 \\
\hline
\end{tabular}

${ }^{*} V$ s. control group, ${ }^{\dagger} \mathrm{MI}$ vs. Cl, ${ }^{* *}$ very significant, ${ }^{* * *}$ extremely significant.

Table III. Lipid characteristics of phenotypes

\begin{tabular}{|c|c|c|c|c|}
\hline Parameter & Phenotype A & Phenotype $A B$ & Phenotype B & Value of $p$ \\
\hline Triacylglycerol (TAG) [mmol/l] & $2.03 \pm 0.98$ & $1.6 \pm 0.65$ & $2.22 \pm 0.74$ & NS \\
\hline Total cholesterol (TC) [mmol/l] & $5.88 \pm 1.33$ & $5.08 \pm 0.92$ & $5.73 \pm 0.89$ & NS \\
\hline LDL cholesterol [mmol/l] & $3.95 \pm 1.09$ & $3.09 \pm 0.79$ & $3.08 \pm 0.42$ & 0.0101 \\
\hline HDL cholesterol [mmol/l] & $1.25 \pm 0.27$ & $1.19 \pm 0.28$ & $1.22 \pm 0.38$ & NS \\
\hline $\mathrm{LDL} / \mathrm{HDL}$ & $3.28 \pm 1.21$ & $2.70 \pm 0.59$ & $2.76 \pm 0.99$ & NS \\
\hline $\mathrm{TC} / \mathrm{HDL}$ & $4.54 \pm 1.80$ & $4.42 \pm 0.84$ & $3.74 \pm 1.28$ & NS \\
\hline Arylesterase/HDL & $47.93 \pm 25.58$ & $32.30 \pm 17.37$ & $35.86 \pm 13.13$ & $0.0926, \mathrm{NQS}$ \\
\hline Uric acid [mg/dl] & $5.80 \pm 1.15$ & $4.97 \pm 1.52$ & $4.11 \pm 1.34$ & 0.0361 \\
\hline CRP $[\mathrm{mg} / \mathrm{l}]$ & $26.6 ; 26.6-177$ & $10.9 ; 9.68-31.4$ & $96.5 ; 13-180$ & 0.0171 \\
\hline
\end{tabular}

a positive and significant correlation was found in the $\mathrm{AO}$ group for HDL-chol and PON1 arylesterase activity $(r=0.3804, p=0.0185)$. No significant correlations were observed for the arylesterase/ $\mathrm{HDL}$ ratio either between $\mathrm{MI}$ and $\mathrm{Cl}$ groups or after dividing into phenotypes (Tables I and III).

\section{Paraoxonase activity}

The data from the AO group obtained for paraoxonase and paraoxonase stimulated activities were not sampled from the Gaussian distribution; thus nonparametric methods were used for their statistical evaluation. A significant decrease in paraoxonase activity was demonstrated in the AO group in comparison to the control subjects (116.81 $\pm 104.53 \mathrm{U} / \mathrm{l}$ and $190.12 \pm 76.73 \mathrm{U} / \mathrm{l}$, respectively, $p=0.0003)$. Further investigations of paraoxonase activity performed within the $A O$ group showed an analogous effect of ischemia, as it was found also for the arylesterase activity, namely PON1 activity in the $\mathrm{Cl}$ group did not differ significantly from that in the MI group, although in both of studied groups the paraoxonase activity was significantly reduced when compared with the control group (Table II). Significant and negative correlation coefficients were found for paraoxonase activity and the concentration of uric acid in the AO group $(r=-0.4922, p=0.0106)$. Stimulated activity of paraoxonase showed a sig- nificant difference between the moderate and critical ischemia groups (Table II).

\section{PON1 phenotyping}

The allelic frequencies were found in the studied groups using phenotype determination, namely the ratio of the hydrolysis of salt-stimulated PON1 activity to the hydrolysis of phenylacetate (Figure $1 \mathrm{~A}$ ). The allelic frequencies presented a trimodal distribution (Figure $1 \mathrm{~B}$ ), and followed the Hardy-Weinberg equilibrium (Table IV).

Evaluation of the predictive effect connected with the presence of low activity PON1 phenotype A showed a significant effect in accordance with ischemia intensity (Table V). It was observed that the $\mathrm{MI}$ subgroup was characterized by a greater number of individuals with phenotype $A$ than observed in the control group, where the phenotype distribution showed equal frequency for both alleles (expected values according to Hardy-Weinberg equilibrium A-8, AB-16, B-8). When the $A O$ group was divided by assigning the phenotype, ANOVA showed that the patients with A phenotype are characterized by the highest concentration of LDL-chol when compared with $A B$ and $B$ phenotypes $(3.95 \pm 1.09 \mathrm{mmol} / \mathrm{l}, 3.09$ $\pm 0.79 \mathrm{mmol} / \mathrm{l}, 3.08 \pm 0.42 \mathrm{mmol} / \mathrm{l}$, respectively, $p=0.0101)$. Similarly, the concentration of uric acid was also significantly higher in the pheno- 

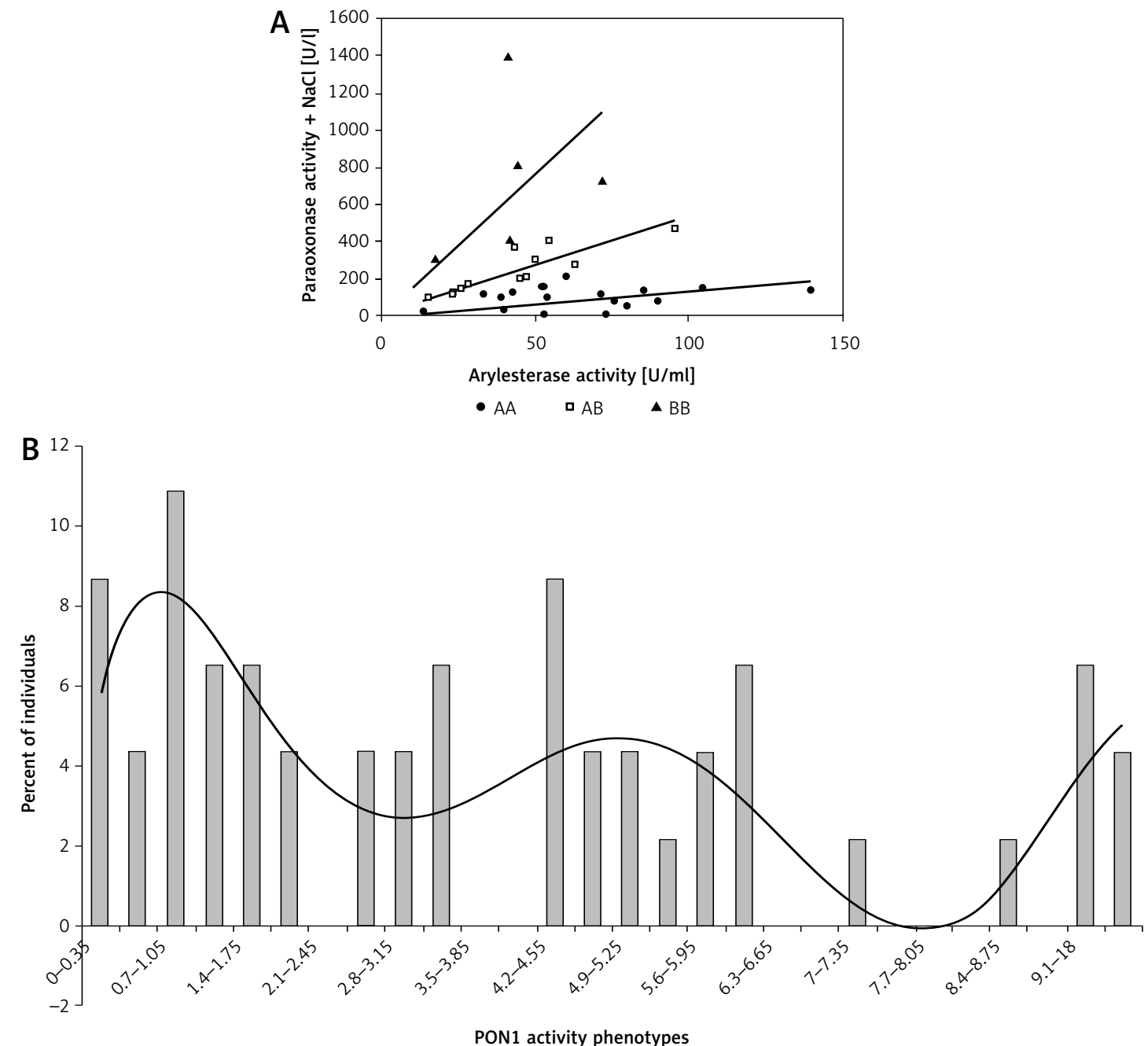

Figure 1. A - The allelic frequencies based on the ratio of the hydrolysis of salt-stimulated PON1 activity to the hydrolysis of phenylacetate. $\mathbf{B}$ - The allelic frequencies presented a trimodal distribution

Table IV. Distribution of paraoxonase phenotypes in AO with respect to Hardy-Weinberg equilibrium $\left(p^{2}+2 p q+q^{2}\right.$ $=1) ; X^{2}=\sum(O-E) 2 / E-$ the chi-square random variable $\left(X^{2}\right)$ equation

\begin{tabular}{|lcccc|}
\hline $\begin{array}{l}\text { Observed number } \\
\text { of individuals }\end{array}$ & $\begin{array}{c}\text { Observed allele } \\
\text { frequencies }\end{array}$ & $\begin{array}{c}\text { Expected geno- } \\
\text { type frequencies }\end{array}$ & $\begin{array}{c}\text { Expected number } \\
\text { of individuals }\end{array}$ & $\mathrm{X}^{2}=\sum(\mathrm{O}-\mathrm{E})^{2} / \mathrm{E}$ \\
\hline Phenotype $\mathrm{A}=23(48.93 \%)$ & Allele $\mathrm{A}(p)=68 \%$ & $p^{2}=46.23 \%$ & 21.73 & \\
\hline Phenotype $\mathrm{AB}=18(38.29 \%)$ & & $2 \mathrm{pq}=43.51 \%$ & 20.45 & \\
\hline Phenotype $\mathrm{B}=6(12.7 \%)$ & Allele $\mathrm{B}(q)=32 \%$ & $q^{2}=10.23 \%$ & 4.81 & $\mathrm{X}^{2}=0.60 \mathrm{NS}$ \\
\hline Total $=47$ & & & & \\
\hline NS - not significant. & & &
\end{tabular}

Table V. PON1 low activity phenotype A association with AO and its intensity

\begin{tabular}{|lccc|}
\hline & OR; $95 \% \mathrm{Cl}$ & $\mathrm{RR} ; 95 \% \mathrm{Cl}$ & Value of $p$ \\
\hline AO vs. control & $2.125 ; 1.96-3.776$ & $1.36 ; 1.072-1.725$ & $0.0143^{*}$ \\
\hline MI vs. control & $2.448 ; 1.336-4.388$ & $1.42 ; 1.125-1.792$ & $0.00631^{\text {** }}$ \\
\hline Cl vs. control & $1.778 ; 1.009-3.132$ & $1.28 ; 1.002-1.635$ & 0.0631 (NQS) \\
\hline MI vs. Cl & 0.72 & 0.9 & NS \\
\hline
\end{tabular}

*Significant, ${ }^{* *}$ very significant, NS - not significant, NQS - not quite significant. 
type A group. Interestingly, the highest concentration of C-reactive protein (CRP) was found in individuals with high activity phenotype B (Table III).

\section{Discussion}

The present study is a continuation of the research carried out on the evaluation of the effect of chronic ischemia of the lower limbs, of different intensity, on PON1 activity in plasma measured with different substrates. The previous results showed the relationship between both arylesterase and paraoxonase activity of PON1 [12] and the intensity of lower limb ischemia as a consequence of atherosclerosis progress. The present results comprise the PON1 status, and provide information on PON1 activities, and the levels of the functional PON1192 phenotypes of the enzyme in plasma.

This study presents, for the first time, the low activity phenotype in relation to the risk of ischemia of the lower limbs due to atherosclerosis. Many works have focused on CVD and CHD [17, 23, 27-29]. There is still little research concerning atherosclerosis of peripheral arteries and the effect of genetic polymorphism and phenotype. Many authors suggest that the PON1 activity phenotypes provide additional information about the risk of vascular disease, not provided by genotype alone [32]. The cardioprotective role of HDL, the inhibition or reduction of atherogenic LDL oxidation, appears to be, in a large part, a function of PON1, which is associated with $\operatorname{HDL}[5,19,23$, 32]. The PON1 metabolizes mildly oxidized phospholipids, presumably by eliminating hydroperoxy derivatives of unsaturated fatty acids [32, 35]. Thus, the PON1-CVD association is expected to result from the role of PON1 in the metabolism of bioactive lipid molecules and protection against the damage caused by oxidized LDL [33]. A number of PON1 polymorphisms have been described, with the Q192R polymorphism markedly affecting the efficiency of substrate hydrolysis. In relation to the Q192R polymorphism, individuals may be homozygous for the $Q$ alloenzyme (Q at 192) or heterozygous or homozygous for the $\mathrm{R}$ alloenzyme ( $R$ at 192) [15]. This phenotype-determining polymorphism is the basis for the dual-substrate enzymatic method, which permits inferences concerning PON1's genotype [20, 21, 25]. The activity of PON1 towards paraoxon (paraoxonase activity) is believed to reflect the Q192R polymorphism (paraoxon is less efficiently hydrolyzed by the $\mathrm{Q}$ alloenzyme) and the variation in the enzyme concentration [15]. Whereas arylesterase activity may be a surrogate for PON1's antioxidant efficiency, paraoxonase activity has been suggested to be a surrogate for its thiolactonase activity [27, $34,36,37]$. In contrast to its antioxidant efficacy, higher Hcy-thiolactonase activity of PON1 is asso- ciated with R192 alleles. Arylesterase activity is believed to represent the enzyme concentration [23], which inclined the authors to apply this activity measured against phenyl acetate in evaluation of PON1 status. Previous research showed that arylesterase activity defines the intensity of lower limb ischemia much more essentially in comparison with paraoxonase activity [12]. The capacity of paraoxonase to hydrolyze lipid peroxides was found to be the reverse of paraoxon hydrolytic activity, showing that phenotype A with low paraoxonase activity is more protective against lipid modification than phenotype $B$. The distribution of paraoxonase activity in the studied population was trimodal and presented low (type A), high (type B) and intermediate (type $A B$ ) activity, which is in accordance with other studies [14, 38, 39]. The odds ratio and the relative risk analysis showed that the patients with moderate ischemia are much more often characterized by phenotype A than phenotype $B$ and the control group. It was shown that low activity phenotype A occurs over twice as often in patients with chronic ischemia of the lower limbs as in people from the control group. Interestingly, phenotype A was prevalent in the group of patients with moderate ischemia. Further evaluation of the phenotype A group indicated significantly high concentration of LDL-chol. However, the CRP concentration was significantly lower in comparison with the phenotype B group, which excludes the intensive inflammatory process in patients with phenotype A. Moreover, the uric acid concentration and arylesterase/HDL ratio, both parameters corresponding to antioxidant and antiatherogenic status, were significantly higher in phenotype A patients. It may be suggested that low activity phenotype individuals despite the unprofitably high LDL-chol are less susceptible to atherosclerosis progression, and resulting intensification of ischemic symptoms. Nevertheless, further investigations concerning larger groups of patients are required. The analysis of PON1 activities in relation to ischemia intensity revealed that the arylesterase activity is more stable and the difference of its level is not significant between the studied phenotypes while paraoxonase activity shows a strong relationship with the genotype. This fact leads to a very wide range of activity values that are observed in all studied groups. We observed the greatest paraoxonase activity towards paraoxon in the phenotype $B$ group and the lowest in phenotype A patients. We suggest that the PON1 status in patients with ischemia of the lower limbs is related to the intensity of the process leading to narrowing of the artery lumen, and thus it may be a helpful factor in evaluation of ischemia of the lower limbs. Therefore we support the idea of Mirdamadi and coauthors, who 
postulated that the PON1 phenotype may be a novel predictive factor for the effectiveness of statin treatment with respect to PON1 activity and serum lipid levels in patients with hyperlipidemia [40]. Statin therapy increased serum paraoxonase activity and reduced triacylglyceride levels effectively; however, this response seemed to be more significant in patients with $A B+B$ PON1 phenotype than in those bearing A PON1 phenotype [40]. Further analysis of the PON1 status in the AO group, especially with critical ischemia, implied invalid ability of the enzyme to reduce the effect of oxidative stress and inflammation, which may correspond with a decreased level of HDL-chol, and increased LDL/HDL ratio and CRP concentration.

Our previous study confirmed the significant contribution of oxidative stress as well as inflammation on the paraoxonase activities in patients with ischemia of the lower limbs [12]. In the Helsinki Heart Study, it was concluded a high LDL/ HDL cholesterol ratio ( $>5$ ) was the strongest predictor of cardiac events [41]. The LDL/HDL ratio in plasma of patients with ischemia of the lower limbs showed a tendency to increase in parallel with the intensity of ischemia, and was found to be the greatest in the $\mathrm{Cl}$ group. The highest $\mathrm{LDL} / \mathrm{HDL}$ ratio was observed in phenotype $\mathrm{A}$ patients, and analogous results were found for TC/ HDL ratio, presented by some authors as another predictive parameter of cardiovascular disease (CVD). The tendency discussed above might result from too low a number of patients studied. However, the evident relationship of lipid parameters and their role in development of atherosclerosisis due to drastically decreased concentration of HDL fraction observed in, i.e Tangier disease or fish-eye disease but not in ischemia of the lower limb, which leads to an evident influence on PON1 activity [2]. Recently it was suggested that the amino acid in position 192 of PON1 participates in HDL binding $[42,43]$. The Q192 alloenzyme was shown to bind to the HDL particle with 3-fold lower affinity than the R192 alloenzyme, consequently showing lower stability, and lipolactonase activity, and a modulatory effect on macrophage cholesterol efflux [42, 43]. A similar observation was made in the present study as well. Both evaluated paraoxonase activities were found the greatest in the group of patients with phenotype B (thus Q192 alloenzyme), and this fact should be helpful to explain the high level of LDL cholesterol in patients with A phenotype (R 192 alloenzyme). However, it does not explain its protective function against ischemia performed by the presence of R192 alloenzyme. Therefore the way of binding the PON1 enzyme by the HDL particle does not determine the beneficial character of PON1 in evaluation of ischemia intensity.
In light of recent reports, the questionable role of $\mathrm{HDL}$-chol in protection of atherosclerosis has been indicated. These results challenge several established views about plasma HDL cholesterol, e.g. that raising of plasma HDL-chol should uniformly translate into reductions in risk of myocardial infarction. Moreover, it is suggested that both acute and chronic inflammation may lead to structural and functional changes of HDL, which render the particles proinflammatory [44]. This discussion on functionality of HDL will probably help to understand some unclear aspects of our PON1 research too. This study analyzed for the first time the PON1 status in ischemia of the lower limbs, showing the potentially important role of PON1 in conclusion of the process leading to intensification of ischemia degree. However, the small number of patients included and some financial limitations are the reason for further studies in this field.

\section{References}

1. Chait A, Han C, Oram J, Heinecke JW. The immune system and atherogenesis. Lipoprotein associated inflammatory proteins: markers or mediators of cardiovascular disease? J Lipid Res 2005; 46: 389-403.

2. Watson AD, Berliner JA, Hama SY, et al. Protective effect of high density lipoprotein associated paraoxonase inhibition of the biological activity of minimally oxidized low density lipoprotein. J Clin Invest 1995; 96: 2882-91.

3. Ng CJ, Shih DM, Hama SY, Villa N, Navab M, Reddy ST. The paraoxonase gene family and atherosclerosis. Free Radical Biol Med 2005; 38: 153-63.

4. Li HL, Liu DP, Liang CC. Paraoxonase gene polymorphisms, oxidative stress, and diseases. J Mol Med 2003; 81: 766-79.

5. Mackness MI, Arrol S, Durrington PN. Paraoxonase prevents accumulation of lipoperoxides in low density lipoprotein. FEBS Lett 1991; 286: 152-4.

6. Shih DM, Gu L, Hama S, et al. Mice lacking serum paraoxonase are susceptible to organophosphate toxicity and atherosclerosis. Nature 1998; 394: 284-7.

7. Tward A, Xia YR, Wang XP, et al. Decreased atherosclerotic lesion formation in human serum paraoxonase transgenic mice. Circulation 2002; 106: 484-90.

8. Shih DM, Xia YR, Wang XP, et al. Combined serum paraoxonase knockout/apolipoprotein E knockout mice exhibit increased lipoprotein oxidation and atherosclerosis. J Biol Chem 2000; 275: 17527-35.

9. Rozenberg O, Rosenblat M, Coleman R, Shih DM, Aviram M. Paraoxonase (PON1) deficiency isassociated with increased macrophage oxidative stress: studies in PON1-knockout mice. Free Radic Biol Med 2003; 34: 774-84.

10. van den Berg SW, Jansen EH, Kruijshoop M, et al. Paraoxonase 1 phenotype distribution and activity differs in subjects with newly diagnosed type 2 diabetes (the CODAM Study). Diab Med 2007; 25: 186-93.

11. Sentí M, Tomás $M$, Fitó $M$, et al. Antioxidant paraoxonase 1 activity in the metabolic syndrome. J Clin Endocrinol Metab 2003; 88: 5422-6.

12. Kasprzak M, Iskra M, Majewski W, Wielkoszyński T. Arylesterase and paraoxonase activity of paraoxonase (PON1) affected by ischemia in the plasma of patients 
with arterial occlusion of the lower limbs. Clin Biochem 2009; 42: 50-6.

13. Keskin M, Dolar E, Dirican M, et al. Baseline and saltstimulated paraoxonase and arylesterase activities in patients with chronic liver disease: relation to disease severity. Intern Med J 2009; 39: 243-8.

14. Elkiran ET, Mar N, Aygen B, Gursu F, Karaoglu A, Koca S. Serum paraoxonase and arylesterase activities in patients with lung cancer in a Turkish population. BMC Cancer 2007; 7: 48.

15. Krzystek-Korpacka M, Salmonowicz B, Boehm D, et al Paraoxonase 1 (PON1) status in gastroesophageal malignancies and associated paraneoplastic syndromes connection with inflammation. Clin Biochem 2008; 41 804-11.

16. Deakin S, James R. Genetic and environmental factors modulating serum concentrations and activities of the antioxidant enzyme paraoxonase-1. Clin Sci 2004; 107: 435-47.

17. Furlong CE, Suzuki SM, Stevens RC, et al. Human PON1, a biomarker of risk of disease and exposure. Chem Bio Interact 2010; 187: 355-61.

18. Roest $M$, van Himbergen $T M$, Barendrecht $A B$, et al. Genetic and environmental determinants of the PON-1 phenotype. Eur J Clin Investig 2007; 37: 187-96.

19. Aviram M, Rosenblat M, Bisgaier CL, Newton RS, Primo-Parmo SL, La Du BN. Paraoxonase inhibits high density lipoprotein oxidation and preserves its functions. A possible peroxidative role forparaoxonase. J Clin Invest 1998; 101: 1581-90.

20. Eckerson HW, Wyte CM, La Du BN. The human serum paraoxonase/arylesterase polymorphism. Am J Hum Genet 1983; 35: 1126-38.

21. Adkins S, Gan KN, Mody M, La Du BN. Molecular basis for the polymorphic forms of human serum paraoxonase/arylesterase: glutamine or arginine at position 191 , for the respective A or B allozymes. Am J Hum Genet 1993; 52: 598-608.

22. Browne RW, Koury ST, Marion S, Wilding G, Muti P, Trevisan M. Accuracy and biological variation of human serum paraoxonase 1 activity and polymorphism(Q192R) by kinetic enzyme assay. Clin Chem 2007; 53: 310-7.

23. Richter RJ, Jarvik GP, Furlong CE. Paraoxonase 1 (PON1) status and substrate hydrolysis. Toxicol Appl Pharmacol 2009; 235: 1-9.

24. Gluba A, Pietrucha T, Banach M, Piotrowski G, Rysz J. The role of polymorphisms within paraoxonases (192 Gln/Arg in PON1 and 311Ser/Cys in PON2) in the modulation of cardiovascular risk: a pilot study. Angiology 2010; 61: 157-65.

25. Mackness M, Durrington P, Mackness B. Paraoxonase 1 activity, concentration and genotype in cardiovascular disease. Curr Opin Lipidol 2004; 15: 399-404.

26. Sanghera DK, Aston CE, Saha N, Kamboh MI. DNA polymorphisms in two paraoxonase genes (PON1 and PON2) are associated with the risk ofcoronary heart disease. Am J Hum Genet 1998; 62: 36-44.

27. Pfohl M, Koch M, Enderle MD, et al. Paraoxonase. Gln/ Arg gene polymorphism, coronary artery disease, and myocardial infarction in type 2 diabetes. Diabetes 1999; 192: 623-7.

28. La Du BN. Future studies of low-activity PON1 phenotype subjects may reveal how PON1 protects against cardiovascular disease. Arterioscler Thromb Vasc Biol 2003; 23: 1317-8.

29. Stefanović A, Kotur-Stevuljević J, Spasic S, et al. Association of oxidative stress and paraoxonase status with PROCAM risk score. Clin Biochem 2009; 42: 617-23.
30. Zielaskowska J, Olszewska-Słonina D. The polymorphism of paraoxonase and its effects in physiological and pathological processes. Adv Clin Exp Med 2006; 15: 1073-8.

31. Mackness B, Davies GK, Turkie W, et al. Paraoxonase status in coronary heartdisease: are activity and concentration more important than genotype? Arterioscler Thromb Vasc Biol 2001; 21: 1451-7.

32. Mackness M, Mackness B. Paraoxonase 1 and atherosclerosis: is the gene or the protein more important? Free Radic Biol Med 2004; 37: 1317-23.

33. Gail PJ, Rozek LS, Brophy VH, et al. Paraoxonase (PON1) phenotype is a better predictor of vascular disease than is PON1192 or PON155 genotyp. Arterioscler Thromb Vasc Biol 2000; 20: 2441-7.

34. Gan KN, Smolen A, Eckerson HW, La Du BN. Purification of human serum paraoxonase/arylesterase. Evidence for one esterase catalyzing both activities. Drug Metab Dispos 1991; 19: 100-6.

35. Deakin S, Moren X, James RW. HDL Oxidation compromises its influence on paraoxonase-1 secretion and its capacity to modulate enzyme activity, Arterioscler Thromb Vasc Biol 2007; 27: 1146-52.

36. Yilmaz N. Relationship between paraoxonase and homocysteine: crossroads of oxidative diseases. Arch Med Sci 2012; 8: 138-53.

37. Beltowski J. Protein homocysteinylation: a new mechanism of atherogenesis? Postepy Hig Med Dosw 2005; 59: 392-404.

38. Paragh G, Seres I, Harangi $M$, et al. Discordance in human paraoxonase-1 gene between phenotypes and genotypes in chronic kidney disease Nephron Clin Pract 2009; 113: 46-53.

39. Patel $A B, P a l R$, Dewan A. Distribution profile of paraoxonase phenotypes among the Gurajatis. Indian J Hum Genet 2007; 13: 65-8.

40. Mirdamadi H, Sztanek F, Derdak Z, Seres I, Harangi M, Paragh $G$. The human paraoxonase-1 phenotype modifies the effect of statins on paraoxonase activity and lipid parameters. Br J Clin Pharmacol 2008; 66: 366-74.

41. Isles C, Paterson J. Identifying patients at risk for coronary heart disease: implications from trials of lipid-lowering drug therapy. Q J Med 2000; 93: 567-74.

42. Gaidukov L, Rosenblat M, Aviram M, et al. The 192R/Q polymorphs of serum paraoxonase PON1 differ in $\mathrm{HDL}$ binding, lipolactonase stimulation, and cholesterol efflux. J Lipid Res 2006; 47: 2492-502.

43. Bhattacharyya T, Nicholls SJ, Topol EJ, et al. Relationship of paraoxonase 1 (PON1) gene polymorphisms and functional activity with systemic oxidative stress and cardiovascular risk. JAMA 2008; 299: 1265-76.

44. Otocka-Kmiecik A, Mikhailidis DP, Nicholls SJ, Davidson M, Rysz J, Banach M. Dysfunctional HDL: A novel important diagnostic and therapeutic target in cardiovascular disease? Prog Lipid Res 2012; 51: 314-24. 